\title{
Research on Traditional Cultural Elements Penetrating into Interior Design
}

\author{
Liu Yijie ${ }^{1, a}$, Li Bohan ${ }^{2, b}$ \\ 1. 2Wuhan University of Science and Technology, Wuhan, Hubei 2015231, China \\ A, b308864991@qq.com
}

Keywords: traditional culture, interior design, decoration, furniture, pattern, material

\begin{abstract}
With the continuous improvement of living environment, people pursues more about the enjoyment and spiritual significance; therefore, Chinese traditional elements take form in modern interior living space and delivers deep neo Chinese style atmosphere, satisfying people's needs on the traditional cultural aesthetic consciousness of modern living space. Meanwhile, designers create "neo Chinese style decorative art" with their wisdom and labor, which enriches us as well as people loving Chinese traditional culture around the world.

Chinese style is no longer old and rigid; instead, it is close to the nature, plain, kind, and simple, but contains abundant meanings. Effect is highlighted only when details are evaluated; in the aspect of residential detailed ornaments, fitment is ignored but decoration is emphasized; especially in the modern structural residence, the decorative effect of different views along the path can often be gained. This kind of decorative method brings more abundant visual effect to the space. Screens, streamers, recessed-leg table with everted flanges, painting and calligraphy, and vessels, and so on, are adopted by designers to local decorations, which reveals patterns with deep Chinese traditional art.
\end{abstract}

\section{What are Chinese traditional cultural elements}

(1) Overview of Chinese traditional culture

Chinese traditional decorative art has long and splendid history, which is an important component of Chinese art; in the long-term process of development and evolution, it forms its outstanding artistic characteristics. It not only shapes the national characters of Chinese descendants, but also pushes the culture and art forward with its unique oriental aesthetic concepts. The traditional elements frequently seen are engraved patterns or designs, window panes and door leaves, Chinese style furniture, embroidery, painting, calligraphy, printing and dyeing, Chinese porcelain, ornaments, and so on, all of which have unique Chinese charm.

Chinese traditional decorative art has a long history, which has different features from the decorative elements in other countries around the world. In the interior decoration of Chinese style architecture, various representative decorative elements and manifested effects of interior design emit deep cultural embience and Chinese unique cultural deposits; the generous model structures, abundant content and deep significance makes it widely applied.

The place of traditional decorative elements can be obviously seen in the ancient and modern Chinese style interior design; they are also indispensable representative elements, integrating double qualities of solemnness and elegance. As the symbol of interior design structure, the commonly seen engraved patterns or designs, window panes and door leaves, Chinese style furniture, embroidery, painting, calligraphy, printing and dyeing, Chinese porcelain, ornaments, and so on, exert unique artistic charm in the interior design forms and are loved by people. Moreover, besides the transmission in the effect of visual decoration, the auspicious patters of traditional decorative elements contain people's hope for beautiful life in terms of spacial structure, such as the application of symbolic implications of "plum", "orchid", "bamboo", and "chrysanthemum". Such decorative patterns as lily, pomegranate, mandarin duck, crane, bat, fish, and son on are commonly seen; lily means a harmonious union lasting a hundred years; pomegranate indicates many sons and grandsons; mandarin duck symbolizes conjugal affection; crane represents good health and a long 
life; "bat" has a similar sound with "blessing" and "fish" sounds like "surplus", which mean many blessings and richer and richer every year. Even in modern times when science is valued, these Chinese decorations which symbolize people's anticipation for beautiful life are still loved by many people.

(2) Aesthetic value of Chinese traditional culture

Chinese elements are widely applied in interior design prosperously for such a long time; the reason is that Chinese elements not only have anesthetic values in the form, but also contain a kind of beauty of traditional culture. In China with thousands of years' history and culture, Chinese traditional interior decoration also has long history. Chinese traditional interior decoration shows solemn and elegant style or intangible and graceful style; but the core is the cultural ethos in Chinese people's blood. In the cultural spiritual level, these two decorative styles represent the ideological essence of Confucian and Taoist thoughts in Chinese traditional culture. Confucian thoughts advocate the positive ideas of taking the world as individual responsibility and trying to realize self-worth; under the influence of the idea of "benevolence", Chinese elements are widely applied with smooth and steady, solemn, satisfactory, and joyous features in interior design. However, Taoist thoughts emphasize that the Tao way follows nature and that man is an integral part of nature; influenced by the idea of paying attention to ones own moral uplift without thought of others, the style of interior design tends to pursuing the harmony of human beings and the nature, with intelligent, unconventional and elegant features. These two thoughts supplement each other, making the cultural beauty in Chinese elements include human society and contain natural harmony at the same time; the aesthetic form is lively and stereoscopic at the same time.

Aesthetic laws of Chinese beauty. Symmetry, balance, orderliness, ratio, mediation, harmony, contrast, and rhythm, are all the laws of formal beauty. However, the formal beauty of Chinese elements are rather outstanding in such three aspects of symmetry, balance, and harmony. Taking symmetry as beauty, the decorative patterns containing Chinese elements are simple, practical and easy to handle in interior design; the proportional aesthetic idea of "one hundred chi for shape and one thousand chi for force" is fully valued in Chinese traditional architecture, and therefore, in interior design, only those Chinese elements with proper ratio can fully give fully play to the aesthetic culture; as for harmony, it shows a sense of wholeness, which is greatly valued in Chinese elements.

In interior design, besides furniture, some decorations adopt Chinese elements, which are called as Chinese style decorations. Chinese style decorations mostly have symbolic significance and contain certain Chinese traditional cultural connotations.

\section{Applications of traditional cultural elements in modern interior design}

(1) Application of traditional patterns in interior design

Traditional patterns are applied in walls through such methods as mural, decorative picture, wood carving, hanging panel, decorative angular line, overall fitment, and so on. Mural is generally used in comparatively large public space; as for patterns, taotie (a mythical ferocious animal) pattern, beast-face pattern, green dragon pattern, and so on can be selected, and wood-carving print and architectural print can also selected. Partition wall belongs to half-entitative space interface, whose forms are partition, septum, screen, and so on; it usually has decorative effect on the basis of satisfying the using functions. As for the patterns on partition wall, we can choose simple and bright geometric patterns, such as cracked ice pattern, square patter, or characters, landscape, dragon and phoenix pattern, and so on.

Decorative patterns are more widely applied in domestic furnishings. Decorative patterns are applied in furniture, mural, handwork, decorative fabric, and so on. As for furniture, plants and animals are mainly used; as for fabric, flower and plant patterns, phoenix and bird patterns are mainly applied; as for mural, various patterns are applied; as for ceramic decoration patterns, flower, bird, and plant patterns, dragon and phoenix patters, and so on are mainly applied.

Traditional decorative patters are rarely applied in ceilings and floors; small local decorations can be selected. 


\subsection{Classification of traditional patterns}

Since ancient times, people add various patterns to increase the sense of depth of houses in the process of house fitment, so as to increase the beauty of house decoration. Meanwhile, the addition of traditional patterns can increase the practicability of houses to a large degree; especially for some houses with high beams, the proper addition of some traditional patterns can effectively decrease the height of beams; meanwhile, houses can increase soundness and firmness. In the long-term living practice, ancient people divide the traditional patterns applied in house interior and outdoor designs into human figure pattern, animal pattern, plant pattern, utensil pattern and various paper-cut patterns.

1.1.1 Figure pattern: in the application of traditional figure patterns, the figures are brave and skillful in battle and come from fairy tales, such as Zhao Yun, Guan Yu, Zhang Fei, and other figure stories, and so on.

1.1.2 Animal pattern: besides figure pattern, animal pattern also has rather important application in interior and outdoor fitment. Animal patterns are mainly some animals with good implications or great power, such as magpie, tiger, lion, and so on.

1.1.3 Plant pattern: plant pattern has rather specials implication in the application of interior and outdoor fitment, where hard-working peasants draw pictures on their houses, such as rice, wheat, sorghum, and so on, indicating beautiful hope for good harvest in coming years or generations. Meanwhile, some plant patterns with good implications are also applied in the fitment of architecture, such as bamboo, orchid, plum, and chrysanthemum, symbolizing good qualities of conducting oneself and treating other people calmly and lightly.

1.1.4 Utensil pattern: as China has long history, the utensil industry is also advanced. As is known to all, China's porcelain is popular around the world; therefore, in the design of many buildings, people apply various utensil patterns in it, which can increase the buildings' sense of history and cultural implication at the same time of inheriting Chinese culture.

1.1.5 Paper-cut pattern: paper-cut pattern, as an important part of Chinese long culture, has important application in architectural design. Paper-cut pattern is mainly designed according to folk customs, including such animal patterns as centipede, snake, and so on, as well as popular coloured lantern patterns in various festivals.

1.1.6 Other patterns: besides the traditional patterns above, there are also some special traditional patterns applied in some buildings. For example, patterns of natural phenomena, patterns of water wave, patterns of cloud, and so on. The application of this kind of patterns aims to make buildings and architecture grand and imposing, and with the spirit of times.

(2) Main application of traditional patterns in interior and outdoor design

2.1 Application of traditional patterns in ceilings

Ceiling is one of the important parts in houses and buildings, the design of which influences the living area and the overall look of the whole house. Ceiling mainly refers to the part over beam in houses, which also means the "top" or "cover" of the whole house. In the design of ceiling, it mainly applies "paper-cut patterns" or various colored drawing patterns to decorate. Generally speaking, the pattern area decorated by interior ceilings is rather large, and the color or material of patterns is relatively mild and suits people's aesthetic needs.

2.2 Application of traditional patterns in door and window

In the general house construction, door and window are important parts of house design, the quality of which also influence the lighting and ventilation of the whole house. Traditional patterns are also widely applied in house design; especially in some independent houses, it is more obvious. All the aspects of door and window can be decorated with patterns. Under many circumstances, door plank is decorated by various figure patters as the most important part of door, symbolizing good wishes of welcoming beautiful things.

2.3 Application of traditional patterns in floor and wall

The application of Chinese traditional patterns in house design can reflect on the floor and walls in a great aspect. It mainly aims to increase the beauty of houses and it also has important effect on the overall structure and design of houses. The proper and effect pattern application can not only 
increase the decoration effect of houses, but also have practical effect. For example, if we design and draw certain patterns on the floor, slips can be avoided well and houses become more practical. The application of traditional patters is mainly shown in sensitivity and design; meanwhile, the design for the whole house also has good display effect and the overall style of house can be increased.

\section{Application of traditional furniture in interior design}

As an important component of interior design, furniture is a typical representative of applying Chinese elements in interior design. As for the furniture with Chinese elements, we call as Chinese style furniture. After thousands of years' development and inheritance. Nowadays, Chinese style furniture has become the classics after great waves sweeping away sand, among which table, chair, bed, and desk are typical representatives of Chinese style furniture.

Western design field believes that, "without Chinese elements, there is no noble temperament." Chinese style furniture has strong expressive effect on the rooms and it can decide the style of this place at any place. In modern interior design, stable, steady, plain and simple traditional furniture can be adopted and its geometry patterns echos to traditional lattice window and door headers; variant furniture design coordinates with modern Chinese interior living environment and life style. Variant furniture draws the modeling elements and cultural symbols of traditional furniture, and at the same time combines with the manufacturing techniques of panel furniture and solid wood furniture; in this way, it keeps the artistic effect of elegance and delicacy of traditional furniture and is equipped with the concise style and function of modern furniture at the same time, which can be widely applied in interior design.

3. Application of traditional painting and calligraphy in interior design

(1) Different effects of traditional painting and calligraphy in interior design

Different painting and calligraphy works can adjust mood; of all ages, there is a saying of "poems and paintings have the same source"; for example, a piece of painting and calligraphy works of Du Fu's Jueju, "two orioles sing in green willows, and a line of egrets flying in the blue sky. The snow of thousands of years on the western mountain can be seen from the window, and the boats traveling ten thousand miles are located at the door", which can make people feel the scenery of natural beauty, the broadness of space, and the thriving picture of coming spring and see a landscape painting and genre painting combining far and near, long and temporary. Li Qingzhao's prose Rouged Lips, "at the sight of strangers, the girl's socks slip and gold hairpin drops, walking away shyly; the girl leans against the door and pretends to smell the green plum", shows a lovely, innocent, sweet and a little naughty maid on the paper with deep emotions, which makes people laugh. Different works are provided for people with different temperaments; for example, introvert and prudent people or people living in dry area can choose paintings which make people feel moist and watery, and they can choose broad prairie, ocean to get harmonious and comfortable effect; people with open personality can choose forest and field to cultivate their taste.

(2) Decorative feature of modern painting and calligraphy in interior design

With people's life getting rich and cultural qualities elevating, many families and hotels use painting and calligraphy works to decorate living space and beautify different functional space to increase the artistic atmosphere of living space; this kind of decorative form has become a kind of fashion trend.

Painting and calligraphy works are elegant artwork, which can satisfy various people's pursuit for culture; the traditional painting and calligraphy art in modern living space is not only traditional Chinese art paper paintings, mounting pictures, and hanging paintings, and traditional painting patterns are shown on textile fabric to make fabric art wares; writing brushes can also be adopted to paint on main walls to emphasize design themes.

4. Application of traditional materials and colors in interior design

The selection and design of interior materials also needs to embody traditional culture and values; Chinese traditional cultural perspective believes that everything is constituted with five basic elements of gold, wood, water, fire, and soil, the colors of which are five colors of green, red, yellow, white, and black; these five elements inter-promote and inter-restrict each other; then, in the 
design of material and color should not only consider senses, but also draw on advantages and avoid disadvantages, according with the characteristics of mutual promotion and restraint between the five elements, so as to create harmonious interior environment. Therefore, in the selection of material and color and the decoration, at the same time of satisfying the functional needs, it is necessary to keep the natural characteristics of various materials, instead of too much artificial embellishment. The decoration of material and space should try its best to obey the principle of mutual promotion and restraint between the five elements to organize deployment, so as to influence people's mind and body through adjusting the environment of interior space and to reach the effect of the harmony and balance of nature.

\section{Application methods of traditional elements in interior design under the background of new techniques and materials}

Material is the material basis and means of realizing design plan and conception. Nowadays, with the development of technology, the materials that can be used have many varieties, such as wood plastic composite, glass, fabric, and so on. Different materials can embody different texture effect, giving people different aesthetic perception; the combination of different decoration materials with traditional patterns can not only enrich decoration effect, but also reflect spirit of modern times. For example, traditional decorations often take wood structure to express the shape and condition, but as timber resource lacks nowadays, human beings will continuously adopt new materials to replace the original wood. At the same time of new materials are constantly applied in designs creatively, we should also try new applications of traditional materials. Take bamboo wood as example. Bamboo wood, as a kind of fast-growing green and environmentally friendly material, has wider and wider applications, such as bamboo floor, bamboo furniture, bamboo artwork and bamboo manufacturing series. The special environmental protection property and cultural characteristics of bamboos can not only have ornamental value in interior decoration design, but also make people have the feeling of coming back to the nature; meanwhile, people can still feel the strong atmosphere of Chinese traditional culture.

\section{Conclusions}

We should rediscover and inherit traditional culture and make perfect combination with modern life style, to make our interior design works not only satisfy modern people's material pursuit and life ideals but also embody Chinese traditional cultural thoughts and values.

All in all, Chinese traditional decoration elements exert important influence in the expression and application of interior design's aesthetic values and design thoughts. Especially in the design and developing trend of modern spacial environment, the elements will move forward with the times' development, the social improvements, as well as the advancement of human beings' improvement in spiritual and material cultural life style.

School of Art and Design in Wuhan University of Science and Technology Liu Yijie Li Bohan

This paper is funded by the project of teaching and research in ministry of education, project name: research and practice of course system of visual communication design major based on Chinese traditional culture, project No.: 2015231

\section{References}

[1] Huang Guotao. Application of soft decoration in interior design [J]. Shanghai Industrial Art. 2011.

[2] Li Renwei. "Low carbon" confusion of interior design [J]. Art Education Research. 2011.

[3] Chen Hongyu, Liu Fei. Spacial rebuilding of images in the regions south of the Yangtze River.

[J]. Decoration. 2007. 
[4] He Chao. Discussion on the composition and design of interior space in houses. [J]. Popular Literature. 2011.

[5] Xue Lina, Liang Tao. Application of minimalism of solo in modern interior design. [J]. Popular Literature. 2011.

[6] History institute of Chinese architectural design and research institute. Zhejiang dwellings. Chinese Construction Industry Publishing House. $2^{\text {nd }}$ edition, May 2007.

[7] Stanley Abercrombie (US). Interior design and decoration [M]. Tianjin: Tianjin University Press, 2006.

[8] Ye Lang. Outline of history of Chinese aesthetics [M]. Shanghai: Shanghai People's Publishing House, 1985.

[9] Xu Xin. Traditional pattern design [M]. Jilin: Jilin fine arts press, 2000.

[10] Chen Xinsheng. Traditional art and modern design [M]. Anhui: Hefei University Press, 2005.

[11] Hui Gu. Application of traditional patterns in modern design [M]. Liaoning: Liaoning Fine Arts Publishing House, 2002.

[12] Zheng Jun. Chinese decoration art [M]. Beijing: Higher Education Press, 2001. 